\title{
The Effect of Spirituality on Adjustment to Chronic Breast Cancer: Case Study \\ Reza Pourhosein $^{1 *}$, Aida Farsham ${ }^{2}$
}

${ }^{1}$ Associate Professor, department of Psychology, University of Tehran, Tehran, Iran

${ }^{2} \mathrm{PhD}$ student, Department of Psychology, University of Tehran, Kish campus, Kish, Iran

DOI: $10.36347 /$ sjahss.2021.v09i05.005

| Received: 26.03.2020 | Accepted: 04.05.2021 | Published: 18.05.2021

*Corresponding author: Reza Pourhosein

Abstract

Case Report

Introduction: As a chronic disease, breast cancer may reduce the resilience of the patient and cause a lot of bitterness to and make her lose hope in life. These patients need to cope with the chronic illness to continue their life calmly. One of the factors that cause compatibility is spirituality. The purpose of this study was to investigate the effect of religious belief and spirituality on the effective compatibility of chronic breast cancer patients. Presentation Case: The subject is a 54 - year - old Muslim, married and has two children, diagnosed with breast cancer disease from the progressive type that has been undergoing surgery, radiotherapy and also chemotherapy. This woman has religious beliefs, scrupulously does religious practices and rites. Spirituality and worship are an important part of her life. Conclusion: This study was conducted with a phenomenological approach and using in-depth and semi-structured interview. The results of this study emphasize that religious belief and spirituality have managed to keep the patient's positive outlook on life. It was found that spirituality has led to the awareness of illness without experiencing stress. Spirituality has increased the patience and endurance of the patient to face cancer difficulties. Therefore, teaching spirituality and correcting negative attitudes toward life in chronic patients provides them with compatibility to continue their life.

Keywords: Breast cancer, chronic diseases, Spirituality, Adjustment.

Copyright $($ C) 2021 The Author(s): This is an open-access article distributed under the terms of the Creative Commons Attribution 4.0 International License (CC BY-NC 4.0) which permits unrestricted use, distribution, and reproduction in any medium for non-commercial use provided the original author and source are credited.

\section{INTRODUCTION}

Chronic diseases are one of the most important health and psychological problems of societies and is considered a major source of health and imposes a lot of economic expenses on society [1]. The chronic diseases affect the compatibility and functionality and social presence of the patient.

Chronic diseases have many kinds. One of the most important of these diseases is cancer [2]. Cancer is one of the major health issues in the world, with the threat of human health and active life in different ages, individual, family and social damages in physical, psychological and spiritual dimensions [3].

Among the types of cancer, breast cancer is a common, malignant and progressive disease that affects different aspects of the life of the patient. This cancer is the most common type of cancer among women around the world and it accounts for $25 \%$ of women's cancers and according to the studies, it covers up to $11 \%$ of all cancers [5]. According to the latest statistics of the cancer research center in Iran, about 8500 new cases of breast cancer were registered annually in Iran, and 1,400 people die from breast cancer. There are currently about 40,000 people living in the country. Most of the patients with breast cancer are faced with a wide range of physical signs and symptoms such as nausea, vomiting, pain, insomnia, anorexia and fatigue [7]. The breast is a symbol of femininity. The idea of losing a breast is unbearable to many women. The reaction of any woman to a suspicious or actual condition may include fear of deformity and loss of charm and fear of death.

The prevalence of psychiatric disorders in women with breast cancer shows that in the early stages of the disease, $36.7 \%$ of them had mood disorders, which included $9.6 \%$ major depression and $27.1 \%$ minor depression. Anxiety disorder was found at 14.6 $\%$ of women detected by $6.8 \%$ in the initial stages and 6 per cent in advanced stages [8].

Compatibility with the complications of breast cancer is very important. Cancer adaptation continues 
from the stage of hearing the news of the infection until the end of the show [9]. Compatibility with cancer is a process that takes place over time. This compatibility is associated with changes in a person's lifestyle. This compatibility is accompanied by changes in the way of a person's life. It refers to a set of attitudes and practices that the individual adopts to maintain health, wellness, feeling of happiness, and overcome the stresses caused by cancer. Individuals from different ways create compatibility [10]. To return to normal life, these patients need help to adapt and meet their disrupted needs. Some compatibility methods are successful in enhancing the sense of health and in others; these processes are useful in the context of creating psychological compatibility [11].

Spirituality is one of the effective elements for coping with a chronic disease, especially breast cancer. The influence of spirituality on mental health has been confirmed in many studies. Spirituality can increase the rate of coping with chronic disease in women and change their attitude toward life. Studies have shown that positive perceptions and spiritual well - being of patients are effective in the prognosis of cancer and has a significant role on hope in cancer patients. So that with having a high spiritual condition, patients feel closer and better with their creator and somehow deal with the imminent separation from their relatives.

In studies reviewed, given that breast cancer is a threat to the symbol of femininity in women, some considered the use of spirituality in life to be useful for the adaptation of people with the disease. In explaining this issue, it can be said that spirituality is associated with reducing stress and increasing the feeling of security and peace and satisfaction of basic needs; and religious people use more effective coping methods in dealing with environmental stresses [7]. The results show that the complications of cancer are lower in patients with higher spiritual health. In cancer patients, meaning in life is directly related to physical and spiritual health. For cancer patients who are in the final stages of their disease, spiritual and religious peace may be even more important than physical and mental health [12]. The study showed that spiritual health had a very significant effect on the end-of-life despair of cancer patients. People with spiritual health are capable, strong, have more control and social support. spiritual health is only associated with hopelessness and may prevent her from committing suicide and somehow give meaning and stimulus to these patients' life which is full of stress and sadness, and in addition to mental and psychological problems, some physical problems can also be overcome.

In this research, we seek to investigate the effect and result of spirituality in a patient with breast cancer who has undergone a surgery.
The research method is a single study with a phenomenological approach. In this study, semistructured and in-depth interviews have been used to obtain the patient's attitude and psycho-structures towards the disease and her view of life, as well as how the person adapts to the disease.

\section{CASE REPORT}

The case study is a 54 - year - old married woman with two children. She is Muslim and Muslim believer who has a great regard for her religious behaviors. She does all her prayers and religious rites. The family environment in which she is raised is also religious and currently she is living in a religious family. She believes that God helps her cope with the hardship of cancer, and this disease must be a test from the Almighty and she must have patience. For this reason, the patient's spirituality is due to her beliefs and worldview and is not emotional or superficial.

The patient has progressive breast cancer that has undergone surgery on her left breast and is also receiving radiation therapy and chemotherapy According to pathological tests, the scope of his body's involvement with cancer cells has spread to the patient's armpits, as well as his lymphatic vessels. Radiation therapy and chemotherapy are continuing.

The patient is fully aware of the process and prognosis of her illness, and knows all the results of her clinical tests. Accordingly, he accepted the interview with the authors and participated in in-depth interviews with a phenomenological approach. She was aware that the results of this interview will be published in a journal.

\section{DISCUSSION}

After the interview with the patient, its provisions were implemented and coded. In the formulation of the codes, the following general items were obtained:

1. Stress-free experience." When I first heard of the disease and its progress, I was not stressed out," she says. "I only thought that I would experience a new status in my life "..." That's why I received advice from my oncologist for treatment and even surgery."

2. Disease is the medium of human development. The patient studied considers any disease a kind of test which causes mental growth. "I don't welcome the disease, but if I get infected with it, I'm not pessimistic about the system and I consider it a means of spiritual growth" she says. "I know that God will assist me in bearing this disease. I always pray for myself and other patients". ... "It's true that breast cancer is harder for a woman than any other disease, but that doesn't make me lose myself and lose my mood. Of course, my husband's attitude and companionship in this direction has 
contributed to the new situation because he is a religious and spiritual person."

3. Life is beautiful. In the subject's view, life is beautiful and has ugliness and beauty, and suffering and happiness. They accompany each other. "In our Islamic attitude, difficulties and welfare are with each other and cannot be separated. The important thing is the capacity of the human being to tolerate them and bring the threats to the opportunity to enjoy their lives. So the complications can be a means of peace and human success."

4. Life goes on. In the interview with the patient, the point was that the disease is not the end of life and the life continues." Sometimes in life, we face new conditions and situations where we need more compatibility so that we can continue life without interruption and with the previous peace. No crisis should discourage us on the path of life, and reduce our good feelings toward our lives and those around us", she says.

\section{CONCLUSION}

Compatibility with chronic disease helps patients reduce the psychological effects of the disease and not interrupt the routine activities of their individual and social life. Spirituality as one of the important elements of coping with chronic illness has caused the patient, in addition to continuing her regular activities, to express her emotions and feelings in an appropriate way. Compatibility is quite relative and should be defined appropriately based on local and social conditions [1]. Spirituality is one of those conditions that contribute to the patient's compatibility.

It can also be said that increasing the fulfillment of spiritual needs has been effective in effective and life-giving adaptation to the chronic illness. Explaining the findings related to the effectiveness of influential coping strategies in coping with the disease, it can be said that every problem is a problem and every problem has a solution.

Based on this study, people with cancer will need to learn spirituality-based awareness and coping skills and look at spirituality as an effective adaptation method. In this study, it was found that the patient's religious beliefs and spirituality have made it not only easier for the patient to tolerate cancer, but also consider it as a part of her life. In her view, life is both difficult and easy that cannot be separated. In other words, an important factor in the adaptation of such a person is the spirituality and beliefs that have led to her spirituality and religious behavior. In other words, an important factor in the compatibility of such a person is the spirituality and beliefs that have led to her spirituality and religious behavior.
Awareness of the onset of illness is stressful for some patients, and it can be a bitter experience [3]. In this study, spirituality has helped the patient not to be intimidated by the awareness of the disease and its progress. And she believes that her life will continue because it is beautiful, and she will transform the threats to opportunities. In this regard, the physical suffering can also reduce her pain and make her not suffer from mental affliction [7].

\section{REFERENCES}

1. Sahle BW, Chen W, Melaku YA, Akombi BJ, Rawal LB, Renzaho AM. Association of psychosocial factors with risk of chronic diseases: a nationwide longitudinal study. American journal of preventive medicine. 2020 Feb 1;58(2):e39-50.

2. Bullard T, Ji M, An R, Trinh L, Mackenzie M, Mullen SP. A systematic review and meta-analysis of adherence to physical activity interventions among three chronic conditions: cancer, cardiovascular disease, and diabetes. BMC public health. 2019 Dec;19(1):1-1.

3. Jansen MO, Butler KB, Jansen DA. Animation Deformity in Breast Cancer Patients and Mental Health: A Review. Journal of Mental Health \& Clinical Psychology. 2019 Feb 13;3(1).

4. Izzo MC, Bronner G, Shields CL. Rapidly Progressive Vision Loss in a Patient With Breast Cancer. Jama. 2019 Sep 17;322(11):1098-9.

5. Duarte NM, Aguiar P, Faria PL, Bernardo M. Effectiveness of Physiotherapy Intervention on the Quality of Life of Women with Breast Cancer who Underwent Sentinel Lymph Node Biopsy. Open Science Journal. 2017 Oct 12;2(4).

6. Sharifi Saki, Sheyda, Pourali, Ahmad, Aghayousefi, Ali Reza, Mohammadi, Mohammad Reza, Ghobari Bonab, Bagher, and Anbiayie, Robab. Investigating the relationship between patience and self-compassion and depression in women with breast cancer. Scientific-Research Quarterly Journal of Breast Diseases in Iran. 2018; $11(2): 36-45$.

7. Kurian AW, Ward KC, Howlader N, Deapen D, Hamilton AS, Mariotto A, Miller D, Penberthy LS, Katz SJ. Genetic testing and results in a populationbased cohort of breast cancer patients and ovarian cancer patients. Journal of Clinical Oncology. 2019 May 20;37(15):1305.

8. Haskins CB, McDowell BD, Carnahan RM, Fiedorowicz JG, Wallace RB, Smith BJ, Chrischilles EA. Impact of preexisting mental illness on breast cancer endocrine therapy adherence. Breast cancer research and treatment. 2019 Feb;174(1):197-208.

9. Antoni MH, Diaz A, Taub C, Fisher H, Carver CS, Lippman M, Hudson B, Blomberg BB. Abstract\# 2061 Brief stress management interventions after surgery improve psychological adaptation and 
immune cell signaling in breast cancer patients. Brain, Behavior, and Immunity. 2019 Feb 1;76:e6.

10. Griesemer I, Moore E, Khan C, Roche M, Henderson G, Rini C. Psychological adaptation to diagnostic genomic sequencing results: The role of hope fulfillment. Health Psychology. 2019 Jun;38(6):527.
11. Pathak S, George N, Monti D, Robinson K, Politi MC. Evaluating adaptation of a cancer clinical trial decision aid for rural cancer patients: a mixedmethods approach. Journal of Cancer Education. 2019 Aug;34(4):803-9.

12. Jaeger AM, Whitesell L. HSP90: enabler of cancer adaptation. Annual Review of Cancer Biology. 2019 Mar 4;3:275-97. 